Bernhard Brand, Kornelis Blok

\title{
Renewable energy perspectives for the North African electricity systems: A comparative analysis of model- based scenario studies
}

Originally published as:

Bernhard Brand, Kornelis Blok (2015):

Renewable energy perspectives for the North African electricity systems: A comparative analysis of model-based scenario studies 
Bernhard Brand $^{a}$, Kornelis Blok ${ }^{\mathrm{b}}$

\title{
Renewable energy perspectives for the North African electricity systems: A comparative analysis of model-based scenario studies
}

\author{
a Wuppertal Institute for Climate, Environment and Energy, Germany \\ b Ecofys, Utrecht, The Netherlands
}

* Corresponding author: Bernhard Brand, Wuppertal Institute, Döppersberg 19, 42103 Wuppertal, Germany

E-mail: bernhard.brand@wupperinst.org

Phone: +49 202-2492-109

Fax: +49 202-2492-108 


\section{Abstract}

Prospects for the integration of power markets and the expansion of renewable energy have recently triggered a number of publications dealing with transformation scenarios of the North African electricity systems. This paper compares five studies using economic electricity supply- and demand models to assess possible development pathways of the North African power systems from today until 2030 and 2050. The analysis shows that distinct modeling methodologies as well as different approaches to scenario design and parameter assumptions can strongly influence the studies' results, leading to very heterogeneous projections of North Africa's power generation structures as well as the patterns of electricity exchange with other regions, like Europe. Common findings of the studies are that the surplus costs of capitalintensive renewable energy expansion in North Africa can in most cases be offset by avoided fuel costs and avoided investments in conventional power plants. All studies further agree that increased transnational cooperation, notably in terms of market integration and cross-border power exchanges, can bring about important economic advantages for the North African power sector. Renewable energy expansion could also drive electricity exports to Europe, but in integrated power market schemes, such exports only become viable with a very high share of renewable energy exceeding $60 \%$ of the North African power demand.

\section{Introduction}

Electricity generation from renewable energy sources (RES-E) in North Africa has become a prominent topic in the research community. Without doubt, much of the attraction to the issue is owed to the high public profile of the 'Desertec concept' - the idea of large-scale solar power generation from the North African deserts to supply electricity to Europe. The concept, promoted by industry players like the Desertec Industrial Initiative (Dii, 2014), the Mediterranean power grid initiative Med Grid (2014), but also adopted by high-level policy institutions like the Union of the Mediterranean (UfM, 2014), however, remains a subject of controversial debate. Despite a general consensus among experts, that renewable energies will play a more important role in future North African power systems, the detailed scope of RESE deployment remains ambiguous. Opinions particularly diverge about the following questions: What is the realistic expansion pathway for RES-E in North Africa, i.e. what level of RES-E penetration can technically and economically be achieved at which point of time, and how will a future technology mix - renewable, but also conventional/fossil - in electricity 
generation look like? To what extent and under which conditions can electricity exports from North Africa actually be realized?

In the last years, these questions have increasingly been taken up by scientific research, which led to the publication of a number of studies on North African power system scenarios. As will be shown in this paper, the studies' approaches as well as their results are very heterogeneous, and therefore difficult to compare. This was the motivation to carry out a more thorough investigation and systematic appraisal of the publications. Five different studies were analyzed, ranging from relatively brief peer-reviewed research papers to large roadmapping reports from prominent organizations or institutions. In order to present an unbiased picture, a common, uniform comparison methodology was applied to assess the studies' scenario building approaches, modeling methods and model outcomes.

\section{History of the North African electricity supply}

Before starting with the analysis of the different scenario studies, it is instructive to have a look at the historic development of the North African electricity systems in the past. Over several decades, the entire region, encompassing the countries Morocco, Algeria, Tunisia, Libya and Egypt, has been marked by ever-increasing electricity generation. Annual growth rates averaged $8.9 \%$ between 1980 and 1990; 4.5\% between 1990 and 2000 and $6.4 \%$ between 2000 and 2012. As can be seen in Figure 1, by far the largest power producer among the five countries is Egypt, followed by Algeria, Libya, Morocco and Tunisia. The proportions of these five countries have not changed significantly over the years, although economic and demographic parameters as well as population growth and per-capita electricity demand vary substantially from country to country ${ }^{1}$.

$1 \quad$ Electric power consumption per capita (2011 data, World Bank): Morocco $830 \mathrm{kWh}$, Algeria 1090 kWh, Tunisia 1300 kWh, Egypt 1740 kWh, Libya 3930 kWh. Per-capita consumption in the EU is 6030 $\mathrm{kWh}$. 


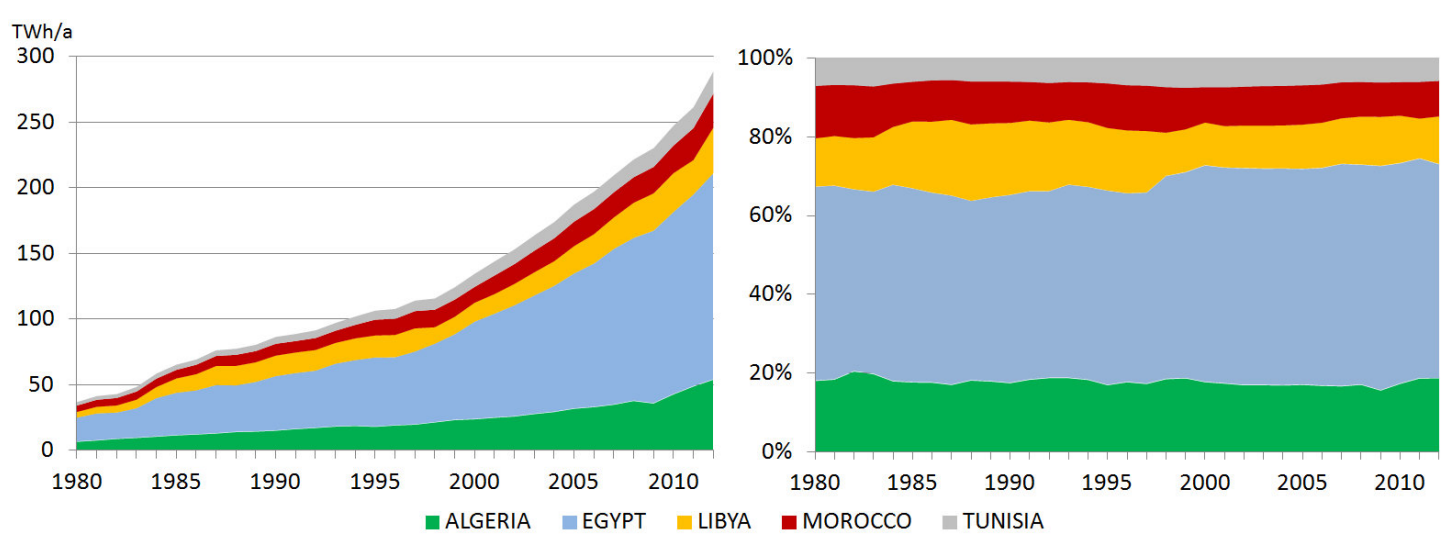

Figure 1. Electricity generation by country. Left: generation in TWh/year, right: percentage proportions. Source: IEA, 2013, annual reports of North African electricity utilities

Looking at the electricity mix by technology (see Figure 2), it becomes apparent that electricity generation in North Africa is still substantially based on fossil fuels. Today, the dominating source of power generation is natural gas (in 2012: 75\% of total North African generation). Since the 1980s, natural gas has continuously increased its share in the generation mix, pushing the formerly predominant, but inefficient and expensive oil ${ }^{2}$ based generation to the second position (in 2012: 15\%). All countries are striving to reduce oil usage in power generation, be it for reasons of cost-cutting (Morocco, Tunisia and Egypt are net petroleum importers) or to save greater quantities of this strategic fuel for export (in the cases of the net oil exporters Algeria and Libya). The shift in the fuel source, from oil to natural gas was eased further by important investments into gas extraction and transmission infrastructure that many gas-rich North African countries carried out in the 1990s in order to promote pipeline-based gas exports. These upgrades also helped to channel more natural gas into the domestic power sector, which has seen a boom in gas power plant projects in the last two decades. The share of coal in the North African power mix (in 2012: 4\%) stems exclusively from Morocco, which, being the only North African country without any noteworthy hydrocarbon resources, had introduced steam coal power plants back in the 1980s, in order to diversify its electricity mix. Hydropower in North Africa (in 2012: 4\%), for the most part, is supplied by Egyptian Nile river hydroelectricity and Moroccan hydro storage power plants. Due to lacking expansion potential, and as other energy sources accelerate production, the proportion of hydroelectricity in North Africa's power mix is set to decline. Non-hydro renewables, hardly noticeable in Figure 2, have only recently entered the North

2 In this article, the term 'oil' stands for all types petroleum-based liquid fuels (e.g. heavy fuel oil, light fuel oil, diesel) that can be used for power generation. 
African power systems. Today, the bulk of non-hydro RES-E generation comes from wind farms, with Egypt, Morocco and Tunisia being the most important producers of wind energy. In 2012 , their aggregated wind electricity production amounted to $2.8 \mathrm{TWh}$, representing about $1 \%$ of the total North African power generation of 289 TWh.

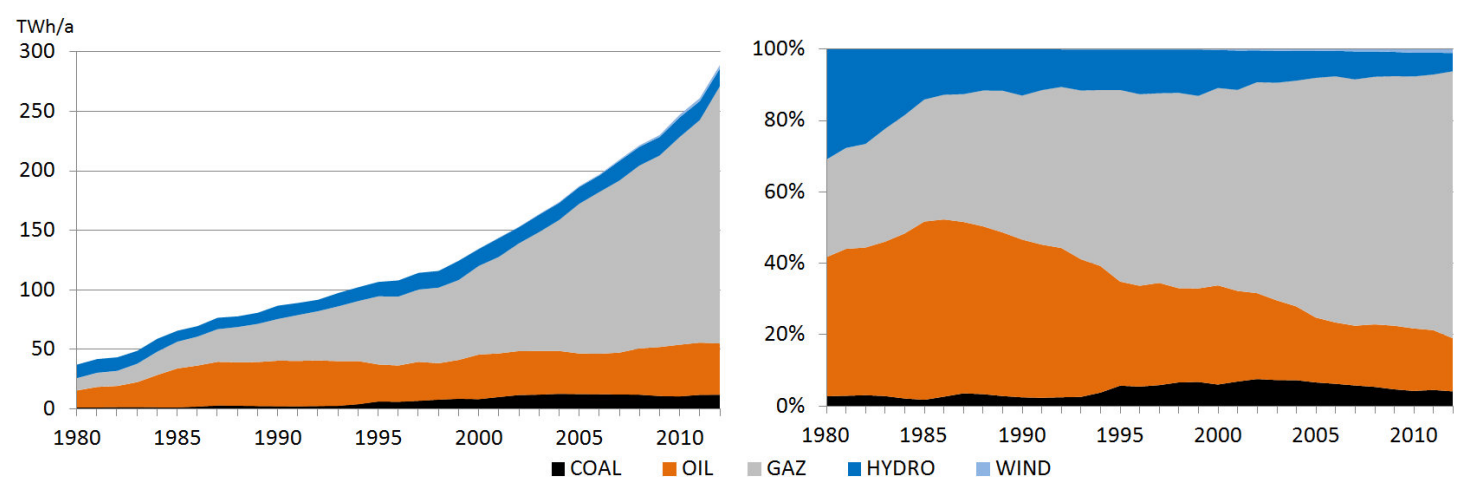

Figure 2. Electricity generation by source between 1980 and 2012. Left: TWh/year, right: percentage proportions. Source: IEA, 2013, annual reports of North African electricity utilities.

Today, as a result of nationally oriented energy policies, the North African power systems are fragmented into five separate electricity markets, mostly ruled by monopolistic state utilities. Despite certain efforts to increase regional cooperation and even the desire to form integrated power markets in the future (Ben Romdhane et al., 2013), the internal exchanges of electricity between the five North African countries are still hovering at a level close to zero (MEDEMIP, 2010). Somewhat more significant are the electricity exchanges between North Africa and its neighboring regions Europe and the Middle East. In 1997 and 1998, first electricity interconnectors were built between Morocco and Spain and between Egypt and Jordan. Over the past 15 years, the exchange of electricity across these power links has shown a net import balance of North Africa, which on average meets around 1\% of its demand from abroad (see Section 5.4).

\section{Trends, influencing factors and uncertainties of North African power system development}

Forecasting the future of North Africa's electricity generation based on historic developments is certainly sketchy, but the observations outlined above nevertheless give some indications about likely trends in the near term. One of the trends with the highest inertia is certainly the growing electricity demand, which, as the developments of the past have shown, is still far 
from saturation in North Africa. Although exact growth rates are difficult to predict, the trajectory in Figure 2, suggests a general continuation of the demand increase. A second, very certain pattern concerns the stagnation of hydro power in the North African power mix. Furthermore, liquid fuels (fuel oil, diesel) are also set to decrease their contribution to the North African electricity mix: Old, inefficient power plants of this type will continuously be replaced by more efficient gas power plants.

Much more uncertainty is associated with the question to what extent can the non-hydro renewable energy sources penetrate into the North African power systems. The favorable worldwide conditions for RES-E technologies (falling costs, improvements in technology) and the immense potential of solar and wind resources in the region speak for an accelerated RES-E expansion in the region, clearly going beyond the current $1 \%$ contribution to the North African power mix. The recent proliferation of renewable target announcements by North African governments (REN21, 2013) additionally underscores the generally positive prospects for RES-E in the region. However, doubts remain as to whether the ambitious policy targets can actually be realized as scheduled - especially in light of the current political and economic difficulties following the Arab Spring. A further open question concerns the choices of RES-E technologies. Wind power, photovoltaic (PV) and concentrated solar power (CSP) are expected to be the leading renewable technologies for bulk power generation in North Africa. However, their exact proportions in the future renewable mix are still a matter of speculation.

The same goes for the conventional fuel mix. While natural gas is set to gradually replace oilbased electricity generation, uncertainty remains about the future of coal in the North African power mix. Morocco already operates coal-fired power plants, but for instance Tunisia, suffering from declining natural gas reserves has also been deliberating the usage of coal for electricity generation (Wuppertal Instiut/Alcor, 2011) - although no final decision on this technology has been taken, yet. Whether carbon-intensive technologies will actually garner support in the region will certainly also depend on the future stance of national governments towards climate policies. Finally, many North African countries have also displayed nuclear ambitions in the past (Jewell, 2011) - which, despite the Fukushima disaster and the recent political upheavals, have never fully disappeared (Haddad, 2011). A likewise highly speculative field is whether the prospects of large-scale intercontinental electricity exchanges, in particular with Europe, could shape the features of the North African power system. The current situation, as shown above, is mostly characterized by electricity supplied from Europe 
to North Africa. However, proponents of trans-Mediterranean, renewables-based electricity systems, postulate that under common political and regulatory frameworks prevailing over the entire EU-MENA region, North Africa could in the future become a major (green) electricity exporter.

Table 1. Summary of broad short-term trends, key uncertainties and the main factors influencing the development of the North African electricity systems

\begin{tabular}{|c|c|c|}
\hline Broad short-term trends & Key uncertainties & Influencing factors \\
\hline $\begin{array}{l}\text { Continuation of growth in } \\
\text { demand }\end{array}$ & $\begin{array}{l}\text { Magnitude of non-hydro RES-E } \\
\text { expansion }\end{array}$ & $\begin{array}{l}\text { General political and economic } \\
\text { situation }\end{array}$ \\
\hline \multirow{4}{*}{$\begin{array}{l}\text { Stagnation of hydro power } \\
\text { generation } \\
\text { Decline of oil-based generation } \\
\text { in the mix }\end{array}$} & \multirow{2}{*}{$\begin{array}{l}\text { RES-E technology choice (RES-E } \\
\text { electricity mix) }\end{array}$} & Power plant technology costs \\
\hline & & Fuel costs \\
\hline & Role of coal power & \multirow{2}{*}{$\begin{array}{l}\text { RES-E cost developments and } \\
\text { economic potential }\end{array}$} \\
\hline & Role of nuclear power & \\
\hline \multirow[t]{5}{*}{ Expansion of non-hydro RES-E } & $\begin{array}{l}\text { Transnational/transcontinental } \\
\text { electricity transmission. }\end{array}$ & $\begin{array}{l}\text { Climate policies of North African } \\
\text { countries }\end{array}$ \\
\hline & \multirow[t]{4}{*}{ Detailed demand growth rates } & Regulatory futures, market design \\
\hline & & $\begin{array}{l}\text { EU-MENA electricity market } \\
\text { integration }\end{array}$ \\
\hline & & Transnational cooperation. \\
\hline & & $\begin{array}{l}\text { Social acceptance of electricity } \\
\text { system transformation strategies. }\end{array}$ \\
\hline
\end{tabular}

Table 1summarizes the contextual framework for building scenarios on the North African power systems. Broad trends for the near-term future - for instance the next decade - can be derived from the historic developments described in Section 2. When it comes to the mid- and long-term timeframe, e.g. as far as 2030 or 2050, any projection is subject to huge uncertainties given the multidimensionality of possible influencing factors. In this context, scenario approaches appear to be the only appropriate tool to imagine and understand potential futures of the North African power systems. At any rate, scenarios need to be designed carefully to be sufficiently robust: This concerns the conception of reasonable political and regulatory frameworks for the scenarios, as well as an assessment of the technical and economical feasibility of the proposed power system transformation pathways. Our article places a particular emphasis on the latter requirement, by assessing publications and reports that use techno-economic energy system modeling methods to portray North African power system transformations. 


\section{Overview of North African electricity system scenario studies}

The literature on RES-E in North Africa has significantly increased in the past few years. Back in the 1990s, energy researchers had started to recognize the huge unexploited solar and wind potential in North Africa and developed strategies how these resources could be harnessed. Early studies were published on this topic in the 1990s by Staiss et al. (1994) and Knies et al. (1999), being the first to propose the exploitation of the North Africa's renewable energies to supply Europe. Czisch (2005) and a series of studies by the German Aerospace Center (DLR 2005, 2006 and 2009), explored large-scale renewable energy generation in the North African region in more detail, likewise including an assessment of the feasibility of RES-E exports to Europe. The leadership of mostly European (German) scholars with their strong stance on electricity exports, has been criticized, for instance, by Supersberger et al. (2010) who state that the 'Western' reasoning about North African electricity issues would exhibit a "too simplified understanding of the political dynamics in the region, largely disregarding the behavior and aims of local actors and stakeholders". Indeed, most of the above-mentioned studies - and many others that followed ${ }^{3}$ - have been predominantly deliberating on North Africa's potential for exporting renewable electricity, but neglected the question how renewable energies can be integrated into domestic power generation schemes. The present analysis is intended to assess only studies that take North African electricity needs into consideration; if power exchanges between neighboring regions (Europe, Middle East) occur, they must take place in a generalized supply-demand regime of integrated electricity systems - not purely for export purposes. By and large, the study is therefore limited to publications that fulfill the following requirements:

- Modeling of supply and demand in integrated electricity systems. The model must consider the domestic power demand in North Africa. Not admitted are studies that only focus on renewable export options (e.g. May, 2005, Trieb et al., 2012, Brancucci et al., 2013) or treat North Africa as a simplified satellite region for the power supply of Europe (EWI/Energynautics, 2011) without sufficiently taking into account domestic electricity consumption patterns.

- Multi-regional modeling: The geographical scope of the studies must cover all five North African countries. Studies that focus only on single countries or smaller clusters of North African countries, for example the Maghreb region (Mercados, 2011; Brand and Zingerle, 2010), are not considered. 
- Inter-temporal modeling: The model must be able to treat power system transformation in a dynamic manner over large timescales starting from the status quo of fossil fuel-based power system infrastructures in North Africa into the future. Not considered are static 'greenfield approaches' that assess the feasibility of electricity system infrastructures at a fixed target year, for example 2050, but omit modeling the respective investment pathways towards such system configurations over the intervening years (Dii, 2012; Boie et al., 2014 or Huber et al., 2012),

A further requirement was that the studies must be sufficiently recent (not older than 5 years) in order to reflect latest developments on North African power markets and to ensure a minimum up-to-datedness of the modeling parameters, e.g. technology costs or fuel prices. At the time of writing, five publications were found that meet these requirements (see Table 2).

\section{1. $\quad$ Dii (2013)}

The study 'Desert Power - Getting Started', a non-peer-reviewed policy roadmap report, explores the transformation of the EU-MENA electricity system to an unprecedented degree of comprehensiveness. Contrary to a previous publication (Dii, 2012), titled 'Desert Power: 2050', the updated study not only demonstrates the feasibility of an (almost) fully RES-Ebased trans-continental electricity network by 2050 - it also provides insights into the details of the transformation processes needed to achieve this end-state. The authors use the costminimizing linear programming model PowerACE, developed by the Fraunhofer Institute for Systems and Innovation Research (ISI), to calculate the optimized power plant dispatch for all 8760 hours of the year across 42 interconnected countries in Europe and the MENA region. Investments into power generation assets and cross-country transmission capacities are endogenously optimized in 10-year intervals, while respecting technological boundary conditions, but also market diffusion constraints. The existing power plant fleet of all involved countries as well as their self-set renewable energy goals by 2020 , were taken into consideration. Most essentially, by the year 2050, an overall emission cap of 194 Mt per year (amounting to average specific emissions of $24 \mathrm{~g} \mathrm{CO}_{2} / \mathrm{kWh}$ ) must be achieved by the entire EU-MENA power system, which is equivalent to approximately $90 \%$ emission reductions compared to 2010 levels. The model uses this central constraint to back-cast the power system transformation between 2020 and 2050 and to calculate the necessary additions in renewable power plant capacity. For the North African countries, eligible RES-E technologies are onshore wind power, PV and CSP power plants. Dii's report contrasts two basic scenarios against each other: One 'Connected' case, where the model is allowed to build additional 
transmission capacities between MENA power systems and the EU, and one 'Disconnected' scenario, where such interconnections are suppressed. An additional scenario variant is the 'Inertia' scenario. Here, connections between MENA and EU power systems may be realized, but in a less extensive manner, as the level of transnational cooperation is assumed to be low and climate action less ambitious.

\subsection{Brand (2013)}

The article 'Transmission topologies for the integration of renewable power in the electricity systems of North Africa', published in 2013, likewise employs a cost-minimizing linear dispatch- and investment modeling approach with an hourly dispatch resolution to explore cost-optimized transformation pathways of the EU-MENA power systems. Having a clear focus on North African power systems, the study features a less refined geographical scope than Dii's Getting Started study (Dii, 2013), covering only the 5 North African countries in detail, while Europe, as well as the Middle East and Turkey are treated as simplified model regions. Moreover, the study is limited to mid-term expansion pathways with a time horizon of 2030. The scenario projections are based on a forecasting approach by which the national RES-E expansion histories, as well as the national renewable energy goals of the North African governments were extrapolated until 2030. The model calculated investments in generation capacities and transnational interconnectors in 5-year intervals, while the daily dispatch as well as the power flows between the countries were simulated on an hourly scale for 24 representative days (576 time segments or 'time slices' per year) in order to take account of the intermittency and seasonal variability of RES-E technologies. One central aim of the study was to analyze the benefits of transnational cooperation on electricity markets. Therefore, simulations were carried out for two different sub-scenarios distinguishing different levels of transnational cooperation and the willingness to set up and share transmission capacities between the North African countries.

\subsection{Fragkos et al. (2012a)}

Researchers at the University of Athens, Greece published a journal article in 2012 dealing with scenarios for the energy systems of the 'MED-9' countries (five North African countries, plus Jordan, Syria, Lebanon and Israel). Titled 'Model-based analysis of the future strategies for the MENA energy system', the publication in large parts corresponds to a previous, EUfunded study by the same authors (Fragkos et al., 2012b) that explored the impact of four 
different high-level trends until 2030 for the South Mediterranean region: (1) A "Reference Scenario", characterized by no noteworthy climate action, a continuation of the present energy policies, and only moderate achievements in terms of RES-E expansion and international cooperation; (2) a scenario labeled "MED-EU Initiatives" where the MED-9 region - through EU support and integrated climate and energy policies - makes substantial progress in terms of RES-E expansion, even resulting in electricity exports to Europe. The "Global Integration" scenario (3) also assumes enhanced efforts with regards to RES-E deployment and climate action, but cooperation mostly takes place in a global, multilateral context, without particular support from the EU. (4) The "Fragmentation" scenario is the most pessimistic case. It postulates a negative macro-economic future for clean energies: Political instability and conflicts hold sway in the region, leading to high risk premiums and a generalized capital shortage - ultimately constraining the countries to maintain and expand existing oil, natural gas or coal power plants instead of investing in renewable electricity generation technologies. All four scenario cases were modeled with the MENA-EDS model, a partial energy market equilibrium model, which had been tailored specifically to portray the MENA region's energy system transformation ${ }^{4}$. As the model covers the entire energy system, not only the electricity sector (which is regarded as a sub-sector of the energy system), the temporal resolution of the power plant dispatch modeling is comparatively low, with only 9 distinct time segments per year. However, the MENA-EDS model indirectly accounts for the interactions between the structure of the power generation system and the evolution of energy supply and demand. For example, massive penetration of PV and CSP technologies in power generation results in changes in generation costs and in electricity prices for end consumers, and thus to changes in the evolution of electricity demand over time.

\subsection{Haller et al. (2012)}

As the study's title 'Decarbonization scenarios for the EU and MENA power systems' indicates, Haller et al. focus on climate policy-motivated scenarios. Similar to Dii's Getting Started study, the authors proceed from the assumption that strong restrictions on carbon emissions - $90 \%$ reduction by 2050 compared to the 2010 levels - hold sway over the EUMENA power systems. The research paper also resembles Dii's study in other ways: Having

4 The MENA-EDS system is basically a derivative of the PRIMES model, which had been used to simulate EU energy policy scenarios in a study by Capros et al. (2014) 
the same time horizon (2050) and using the same modeling approach (linear optimization), both studies also discriminate between the same connection scenarios for the intercontinental transmission systems: A fully integrated, interconnected EU-MENA power system is compared against a scenario where both continents remain without any noteworthy transmission links. The interconnected scenario is labeled "PolGrid", whereas "PolNoGrid" stands for the case where transcontinental power line projects do not materialize. Simulations were carried out with the LIMES-EU+ model, developed by the Potsdam Institute for Climate Impact Research (PIK). Within the geographical outreach of this model are 19 different EUMENA regions; but only two that represent North Africa: Morocco, Algeria and Tunisia are aggregated into one single model region, Libya and Egypt into the other. The model's temporal resolution considers 49 different time slices per year, consisting of 12 characteristic days in 6-hour intervals plus one additional 'super peak' time slice to cover the case where low renewable supply meets high electricity demand. Investments into power system infrastructure - power plants and transmission lines - were simulated in 10-year intervals.

\subsection{OME (2011)}

Authored by the France-based Observatoire Méditerranéen de l'Energie (OME), the non-peerreviewed publication 'Mediterranean Energy Perspectives' presents mid-term energy system forecasts for the Mediterranean region up to 2030. The analysis covers a total of 24 countries adjacent to the Mediterranean Basin, including the five North African countries. OME simulates energy demand-supply equilibriums for the entire energy system by using an econometric model (called Mediterranean Energy Model, MEM). In OME's model, the electricity system is - similar to Fragkos et al.'s study - being viewed as a sub-system of the whole energy system. Expansion of power plant capacity is optimized with a linear programming algorithm minimizing electricity generation costs. Electricity supply/demand is calculated in terms of total, aggregated values without particular consideration of the temporal dynamics (dispatch) of the power system. OME's model considers the following generation technologies: coal, nuclear, natural gas, hydro, wind and solar power. No difference is made between CSP and PV technologies which are both subsumed under the term 'solar power'. OME's study compares two scenarios: A "Conservative" scenario, characterized by a continuation of current policies and rather low efforts towards renewable energy deployment. The "Proactive" scenario, by contrast, stands for strong achievements in the area of energy efficiency and successful implementation of renewable energy projects. In both the 
Conservative as well as the Proactive scenario, OME's study considers nuclear power a realistic option for the North African power systems, with nuclear power plants being deployed until 2030. 


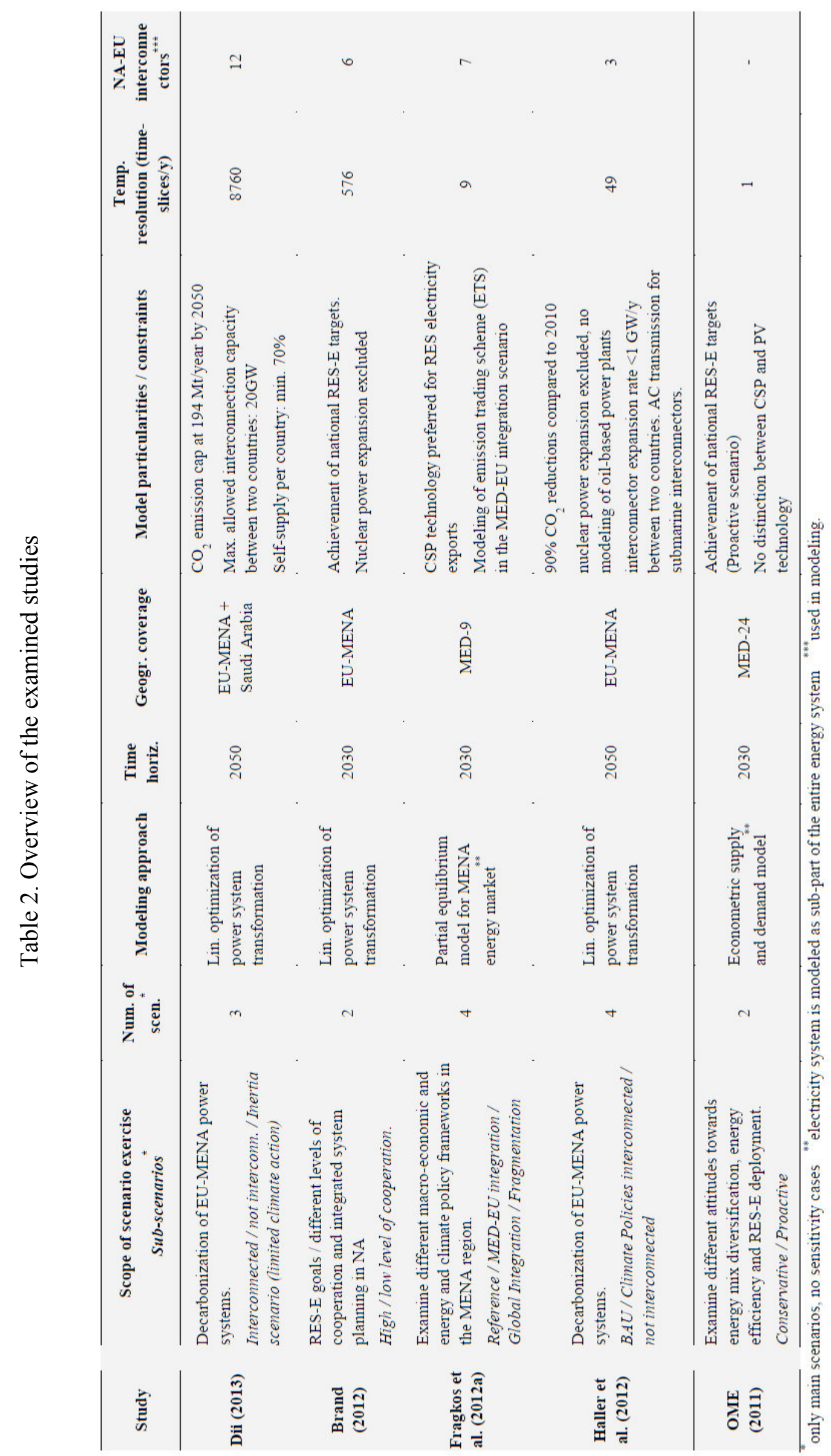




\section{Comparison}

This section summarizes the studies' most significant differences, starting with the assumptions on electricity demand, the generation mixes, carbon emissions, the economic costs and the prospect for electricity exports by North African countries.

\subsection{Electricity demand}

One of the most important factors influencing electricity system modeling is the electricity demand. While there appears to be a consensus that the historic trend of increase in demand will remain unbroken over the next decades, the actually forecasted projections drastically diverge from study to study (see Figure 3) - an indicator that the underlying mechanisms and drivers of the North African electricity demand are still not very well explored. To illustrate the high discrepancies, Figure 3 depicts projections of the Dii study 'Desert Power 2050' (Dii, 2012), the precursor of Dii's 'Getting Started' study (Dii, 2013), which exhibits a tremendously high differential of North African power demand forecasts, ranging from 511 TWh to 1273 TWh by 2050. The high demand scenario rests on historic statistical data of the Arab Union of Electricity, while the assumptions for the low demand result from extrapolations of the "450 Policies" scenario of IEA's World Energy Outlook (IEA, 2011). Both demand assumptions were later rectified in the "Getting Started" study, where a common value, $994 \mathrm{TWh} / \mathrm{a}$, was used as the base for further electricity system modeling. Haller et al. (2012) propose a lower demand, $721 \mathrm{TWh} / \mathrm{a}$, calculated on the basis of historic annual growth rates for the North African power demand ${ }^{5}$.

\footnotetext{
$5 \quad$ Haller et al. (2012) assume that historic demand growth rates linearly decrease to zero until 2050. This results in an average annual demand growth rate of $2.7 \%$ between 2010 and 2050 . For the same period, demand in Dii Getting Started grows by 3.5\% annually. Fragkos et al. (2012a) calculated an average demand growth of 5.8\% per year between 2010 and 2030, while the OME (2011) Proactive scenario assumes an annual demand growth of $3.5 \%$ in the same time period.
} 


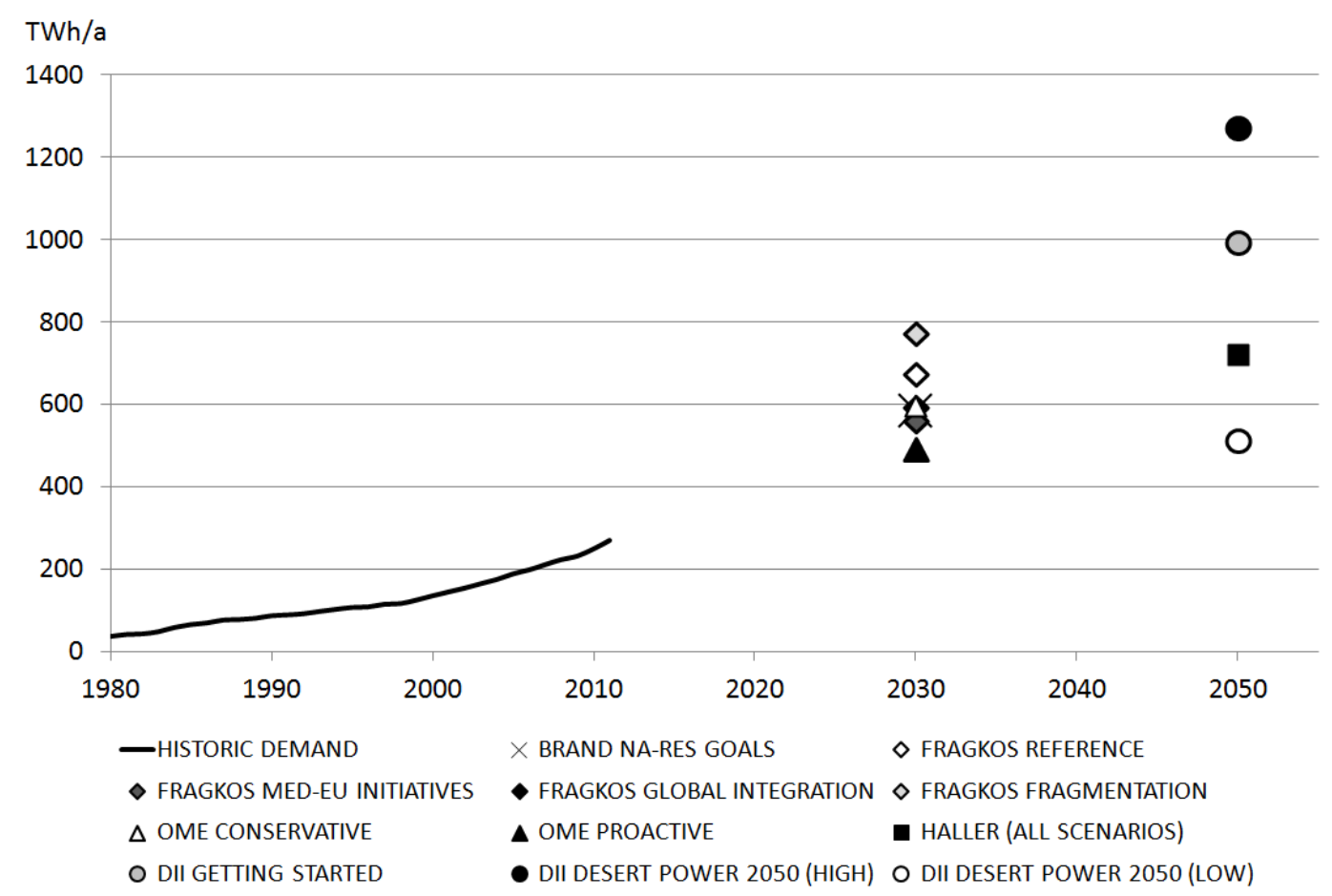

Figure 3. Cumulated net electricity demand (in TWh/a) of the five North African countries.

Contrary to the above-described extrapolation approaches applied by the 2050 scenario studies, the publications with a time horizon until 2030 appear to use more refined demand evaluation methods. In Fragkos et al. (2012a), for instance, electricity demand is endogenously calculated by a supply-demand equilibrium model based on demographic and macroeconomic forecasts for the North African economies. Here, the demand projections range from 560 to $771 \mathrm{TWh} / \mathrm{a}$ by 2030. OME (2011) likewise applies a bottom-up approach, based on GDP and population growth parameters, to calculate the future North African electricity demand. OME's baseline scenario ("Conservative Scenario") assumes a demand of $596 \mathrm{TWh} / \mathrm{a}$ by 2030, while the "Proactive Scenario", due to increased energy efficiency, suggests a lower demand of 491 TWh/a. Brand (2013) does not carry out its own demand assessments, but uses the demand of OME's baseline scenario (596 TWh/a by 2030) for power system modeling.

\subsection{Electricity generation mix}

It is insightful to compare the different studies' resulting power generation mixes. The proportions of the energy sources, as illustrated in Figure 4, give indications about the underlying scenario assumptions and model particularities - and even reveal preferences with 
regards to the technology choices for the North African power systems. The data displayed in Figure 4 was retrieved directly from the publications, or was kindly provided by the authors of the studies.

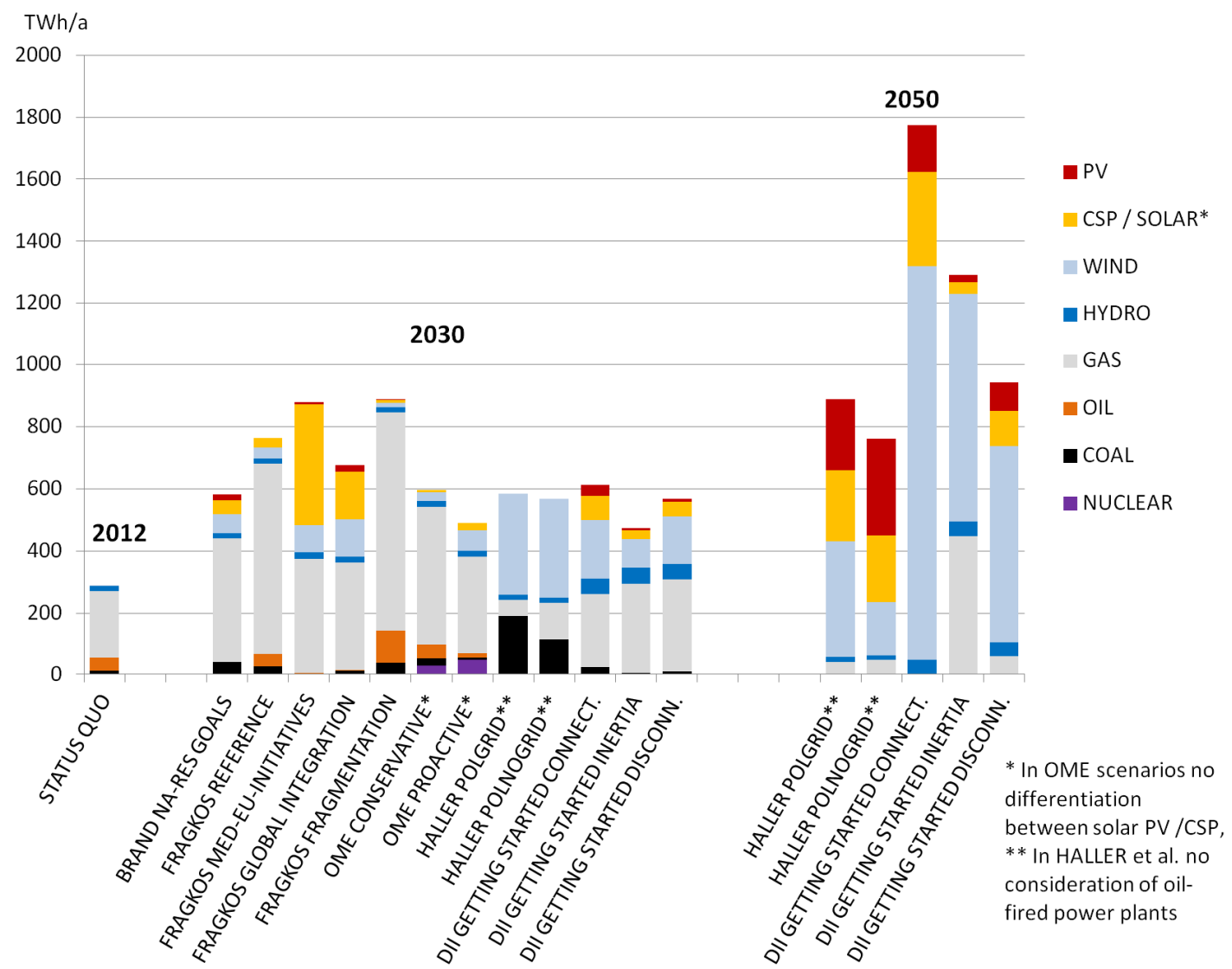

Figure 4. Electricity generation mix of all five North African countries by source, in the different scenario studies (values in TWh/a). Left: studies with 2030 time horizon, right: 2050 scenario studies.

\subsubsection{Generation mix of the 2030 studies}

For 2030, all studies forecast an increasing penetration of non-hydro renewable energies in the North African power generation mix. Even in the most pessimistic case, the "Fragmentation" scenario of Fragkos et al. (2012a), the contribution of wind and solar power at around 25 TWh is significantly higher than the current production, which hardly reaches 3 TWh. The scenario with the highest projected non-hydro RES-E production (481 TWh in 2030 ) is the "MED-EU initiatives" scenario, also by Fragkos et al. The authors assert that the tremendous RES-E growth rates needed to reach this high level ${ }^{6}$ can be achieved by extensive

$6 \quad$ This expansion would require very high annual growth rates for RES-E of over $30 \%$. These are not unrealistic, as similar growth rates have already been reached in the last two decades in other renewable energy markets, for instance in Germany or Spain. 
efforts of North African governments towards climate action and also by massive foreign direct investments (FDI) into renewable power plant projects in North Africa. A major driver for these investments would be EU-supported large-scale green power export schemes from MENA countries to Europe. Most remarkable output in all four scenarios of Fragkos et al. is the strong expansion of CSP, clearly outrivaling wind and photovoltaic power production. The authors explain this to be the result of 'special support' CSP technology would receive in the MENA region, going much beyond the support for wind farms. Likewise, it is claimed that PV expansion is less systematically pursued, because PV could only be built in relatively small units and must be connected cost-inefficiently to the low and medium voltage grid. Although this argument is not fully valid - all over the world, an increasing number of PV power plants already reach the multi-MW scale, including high-voltage grid connection - the CSP bias exhibited by Fragkos et al.'s scenarios in a certain way reflects the current preferences of governments and financiers: Despite dropping prices for PV, international development banks tend to support CSP in the region, while MENA governments continue to stick to dispatchable, storage-based CSP technologies in their renewable electricity roadmaps (e.g., World Bank, 2011). OME (2011) and Brand (2013) forecast a relatively moderate expansion of solar electricity, giving clear priority to wind power as the least-cost RES-E supply option. The same is true for the studies by Haller et al. (2012) and Dii (2013), which likewise clearly favor an initial expansion of wind power on the pathway towards decarbonized North African electricity systems.

Most scenarios agree about natural gas being the main energy carrier for the conventional part of the North African power mixes until 2030. An exception is the study of Haller et al., which projects a comparatively strong penetration of coal power (between $20 \%$ and $32 \%$ of the generation mix), combined with a large share of wind power (56\%), but virtually no PV and CSP contribution. The reason for this surprising 'wind-coal' symbiosis (with a few amount of natural gas needed for balancing) is the still incomplete process of decarbonization by 2030 . Carbon emissions are still allowed to a certain extent by the model constraints; therefore the model seeks a cost-minimizing combination consisting of coal power generation (due to low fuel prices) and wind power as the cheapest low-carbon technology. In the subsequent years, with the carbon constraint becoming more and more restrictive, electricity production using coal will gradually decline (see Section 5.2.2.). Somehow puzzling is the nuclear power supply put forth by OME (2011) in both the "Proactive" and "Conservative" scenarios. From the current perspective, looking at the long lead times for nuclear power plant construction and the instable political situation in the region as well as a rising public resistance against 
nuclear power even in MENA countries (see Haddad, 2011) it appears rather unlikely that nuclear power could come into gear in North Africa as early as 2030.

\subsubsection{Generation mix in the 2050 studies}

As already mentioned, the two studies with 2050 as the horizon, Haller et al. (2012) and Dii Getting Started (Dii, 2013), resemble each other in the modeling methodology (both employ linear programming techniques under similar exogenous carbon emission constraints) and with regard to the scenario design: Haller et al.'s "PolGrid" and Dii's "Connected" scenario assume an interconnected EU-MENA electricity system, while in the "PolNoGrid"/"Disconnected" scenarios, transcontinental interconnectors are suppressed by model constraints. Despite these similarities, the results of the two studies show surprising divergences. The most distinguishing feature is the clear prevalence of wind production in Dii's 2050 mix compared to Haller et al. In all of Dii's scenarios (depicted in Figure 4), onshore wind takes the largest share of the total power generation of North Africa - between $57 \%$ and $72 \%$; Haller et al.'s wind contribution of $23 \%$ to $42 \%$ remains significantly below that. We explain these differences through a substantial cleavage in the studies' wind potential assumptions. In Dii's study, wind generation in North Africa features around 2700 average full load hours by 2050 , while the wind prospects in Haller et al. are much less optimistic with an average of only 1660 full load hours ${ }^{7}$. It is obvious that under the regime of least-cost modeling, this difference renders wind power much more attractive in the Dii scenario, explaining the resulting higher wind penetration in Dii's study. In consequence, Dii's scenarios forecast a clearly more moderate expansion of solar power in the North African generation mix, reaching only a maximum of $26 \%$ in the "Connected" scenario. In Haller et al.'s scenarios on the other hand, CSP and PV make up particularly large portions of the power supply (51\% to $68 \%$ ) - which means a radical change compared to the situation in 2030 where wind still dominates (see Chapter 5.2.1). Likewise remarkable are the different proportions of PV and CSP in the electricity mixes. While in the paper of Haller et al. solar electricity production is mostly oriented towards PV, in Dii's study, a clear preference for CSP can be observed. CSP penetration is particularly strong in the "Connected" scenario, where the North African region exports huge amounts of electricity (see Chapter 5.4.). Apparently, the interconnected scheme favors the installation of dispatchable CSP plants

A likely reason for this is that both studies use different sources and methodologies for wind power assessment (Haller et al.: NCEP/NCAR wind velocity data of 2009, calculated at $80 \mathrm{~m}$ hub height, Dii: MERRA wind data of 2007, hub height $120 \mathrm{~m}$ ) 
offering a higher capability to cater for supply/demand balancing across the different regions of the EU-MENA electricity system.

\subsection{Carbon emissions}

Contrary to most western countries, where the question of carbon emissions reduction is raised in almost any debate about future energy supply schemes, this issue has so far been widely neglected in the approaches to electricity planning of the MENA countries. The scientific literature also barely mirrors the theme: Carbon emission abatement has so far been addressed only by a few MENA researchers (examples Chedid et al., 2001, El Fadel et al., 2012), while western scholars traditionally put more emphasis on this topic. This is also true for the studies analyzed in this paper: Dii (2013) and Haller et al. (2012) explicitly utilize exogenous carbon constraints as the initial position of their modeling approaches for the EUMENA electricity system; OME (2011) considers an increased decoupling of carbon emissions from economic growth in its "Proactive" Scenario, while Fragkos et al. (2012a) assume an emissions trading system (ETS) in the "MED-EU initiatives" scenario with carbon prices also applying to the MENA power sector. A good way to illustrate the consequences of these normative carbon reduction scenarios for the electricity systems is to compare the forecasted emissions of the North African power system with the historic values over the past three decades. Figure 5 depicts the specific carbon emissions in $\mathrm{g} / \mathrm{kWh}$ from 1980 until 2010 (historic values based on IEA, 2012) as well as the projections of the different scenarios for 2030 and 2050. 


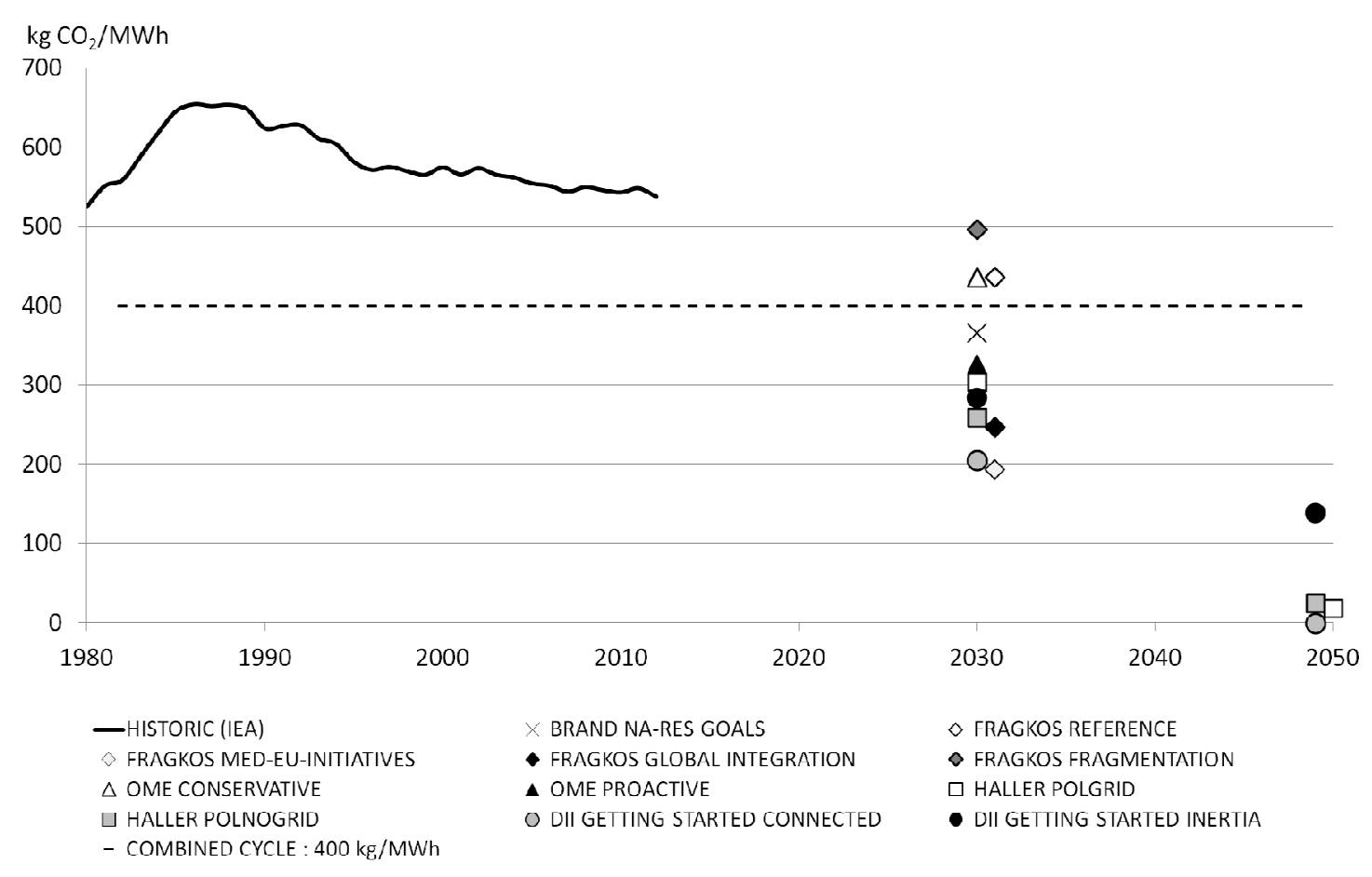

Figure 5. Specific direct $\mathrm{CO}_{2}$ emissions of the North African power systems (kg/MWh). Values only include direct $\mathrm{CO}_{2}$ emissions from fuel combustion in power plants, not life-cycle emissions.

Looking at the historic development, it can be stated that North Africa experienced an increase in specific $\mathrm{CO}_{2}$ emissions until the mid-1980s, but later on succeeded in reducing the carbon intensity of its power system. The initial rise is related to the increased penetration of carbon-intensive power plants (oil, open cycle gas turbine, and coal power) in the North African power mix: Back in 1980, Nile hydropower from Egypt still accounted for around $25 \%$ of the total North African power generation, keeping the specific emissions relatively low. The growing electricity demand in the subsequent years triggered the expansion of conventional fossil fuel power plants, but as no major hydropower generation capacity could be added, the specific emissions consequently increased. In a second phase, after having reached a peak in 1986, the per-kWh emissions of North African power generation decreased. Two factors explain this development: First, the reduced utilization and/or a gradual replacement of oil-fired power plants, and second, a shift to the less carbon-intensive natural gas combined cycle power plants, which are today very popular in North Africa. The average specific $\mathrm{CO}_{2}$ emissions of a combined cycle power plant - $400 \mathrm{~g} / \mathrm{kWh}$ - can be regarded as a 'benchmark' of what could theoretically be achieved in North Africa with an efficiencymaximized conventional power system. Set aside nuclear power and the (unlikely) diffusion of Carbon capture and storage (CCS) technologies in the region, this benchmark could only be undercut by a significant penetration of renewable electricity into the North African power 
mix. As depicted in Figure 5, most scenarios - except for OME's "Conservative" and Fragkos's "Reference" and "Fragmentation" scenarios - afford a very optimistic outlook in this regard, predicting a substantial acceleration of emissions reduction in 2030 and 2050, compared to the current trend.

\subsection{Transmission / electricity exports}

Very often, discussions about the expansion of renewable energy in the MENA region are motivated by the prospect of physical exports of green electricity to Europe. Advocates of this concept assert that the high solar and wind potential in the Southern Mediterranean would render renewable power generation in this region more competitive than in Europe; by importing cheap green electricity from North Africa, so the argument goes, European countries - especially those not so well-endowed with renewable resources - could achieve their RES-E targets more cost-efficiently. This rationale has even been taken up at the political level, for instance by the EU's Directive on Renewable Energies (2009) which explicitly allows EU member states to include RES-E of non-EU origin into their national renewable energy accounting. Despite the presence of this export-enabling framework, the actual reality of North-South electricity transmission looks completely different: For more than 15 years now, North Africa has been a net importer of electricity. At the moment, the main electricity import corridor is an interconnection between Spain and Morocco through which Morocco imported 4.9 TWh in 2012 (ONEE, 2012) ${ }^{8}$, representing around 19\% of Morocco's national electricity demand. The reason why imports from Europe are presently so attractive for North Africa, are price differentials between the North African and European electricity systems ${ }^{9}$. Compared to the gas- and oil-dominated North African power systems, European countries can often produce electricity at lower costs, because their power plant fleets comprise comparatively more coal, lignite or nuclear power plants - all of which operate at low marginal costs. Additionally, the increased penetration of renewable energies into the European power markets brings down prices at the power spot markets (due to the 'merit order effect', Sensfuß et al., 2008), and thus increases the attractiveness of selling power abroad to North Africa. What could be done to reverse this picture, i.e. to increase the economic attractiveness of electricity transmission from North Africa to Europe? It seems

$8 \quad$ To a much lesser extent, electricity exchanges also take place at the eastern end of North Africa: In 2012 Egypt, exported around 780 GWh electricity to Jordan (NEPCO, 2012).

9 For example, Morocco current procures electricity at the Iberian power exchange OMEL because prices are on average $9 € / M W h$ cheaper than the domestic power generation costs in Morocco (Thiam, 2013). 
obvious that to achieve a situation where the markets would favor power flowing from the South to the North, substantially more generation capacity at comparatively lower generation costs than in Europe (e.g., RES-E capacity) must be installed in North Africa. Theoretically, as the RES-E penetration increases, a point should be reached where the North African power generation costs could undercut the costs of European generation (including the costs of transcontinental electricity transmission). From the modeling perspective, it is particularly interesting to quantify what level of RES-E expansion would enable exports from North Africa.

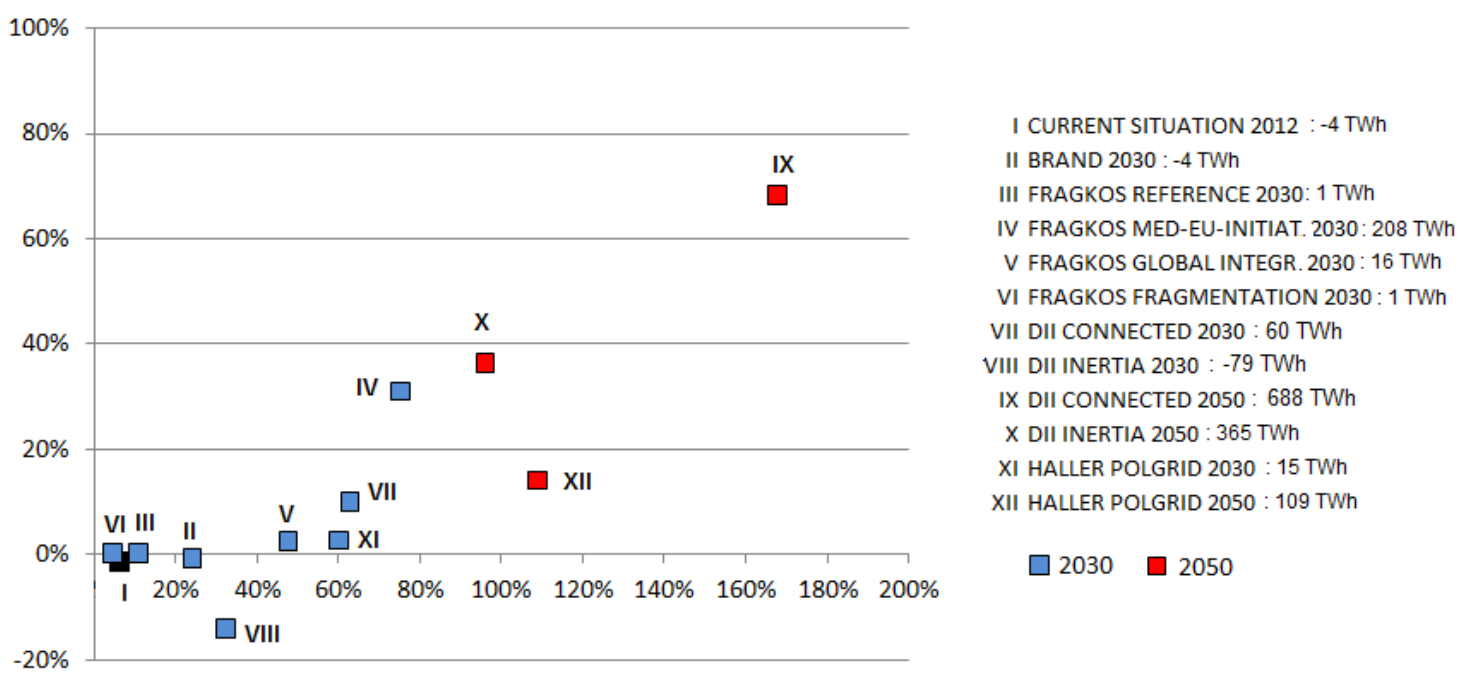

Figure 6. North African net power exports as a function of RES-E penetration (both in percent of the total electricity demand).

Figure 6 summarizes the power exchange projections of the different scenario studies. The net electricity exports of North Africa to its neighbor regions Europe and the Middle East are plotted against the renewable share of the North African power demand at different points in time. It can be observed that up to a level where RES-E covers only around $60 \%$ of the North African demand, all studies predict relatively low exports - or even net electricity imports. For instance in the Dii "Inertia" scenario (data point VIII), North Africa remains a net importer by 2030 , with $14 \%$ of its electricity demand being imported. The paper by Brand (data point I) likewise forecasts net electricity imports by North Africa, though only amounting to less than $1 \%$ of its overall electricity demand by 2030 . Noteworthy electricity exports out of North Africa start when the RES-E generation share in demand exceeds the 60\% level: Beyond this threshold, electricity exports significantly increase. Dii's "Inertia" scenario even performs a remarkable turnaround of the North African electricity transmission 
patterns: While still being a substantial importer of electric energy in 2030 (VIII), by 2050 the region becomes a net exporter (X), sending around 36\% of its electricity demand abroad mostly to Europe, but partially also to the Middle East region and to Saudi Arabia (which only Dii included in the modeling). The switch from imports to exports is realized once there is a reversion of the power generation cost differentials between North Africa and the adjacent regions. Among all scenarios, the most substantial exports are forecast by Dii's "Connected" case (IX), where a very much larger amount of electricity, equivalent to $68 \%$ of North Africa's demand can be exported by 2050. A value rendering the picture of Figure 6 somehow ambiguous is the data point XII, where the "PolGrid" scenario of Haller et al. projects a significantly lower North African export rate (only 14\% of the North African demand ${ }^{10}$ ), despite a relatively high penetration of renewables. This can be explained with the relatively restrictive exogenous constraints concerning trans-Mediterranean grid expansion set by Haller et al. In the North-South direction, Haller et al.'s model only allows three transmission corridors, while Dii's model can add interconnectors at 12 different geographical locations across the Mediterranean. Additionally, Haller et al. limit the model's transmission options to alternating current transmission (HVAC) instead of high voltage direct current (HVDC) technologies - even for subsea interconnectors - which entails higher losses along the transmission path, and hence reduces the attractiveness of electricity exports from North Africa to Europe.

Generally, it can be stated that due to the heterogeneity of the assumptions and modeling approaches, it is rather difficult to draw final conclusions about the exact conditions needed for North African power systems to perform substantial electricity exports. Increasing the RES-E penetration to higher levels as shown above - certainly is one precondition, but definitely not the exclusive factor for leveraging electricity exports out of North Africa. Much will also depend on the power system transformations in the other regions adjacent to North Africa. This not only concerns Europe ${ }^{11}$, but also the Middle East and even the Gulf region, which are striving for RES-E expansion as well. Scenarios examining the interaction of these power systems with the one in North Africa (e.g. through new interconnections between

10 From the European perspective, the electricity transfers from North Africa into 2050 account only for $2 \%$ of the European demand in Haller et. al's "PolGrid" scenario against 14\% in Dii's "Connected scenario".

11 Most studies assume that RES-E expansion in Europe follows the EU National Renewable Energy Action Plans (NREAP). 
Egypt and Saudi Arabia ${ }^{12}$ ) are at the moment not sufficiently explored and further research in this area is undoubtedly needed. It goes without saying that the 'export question' cannot be answered with economic models alone, as it touches upon much more wide-ranging issues such as the political willingness of the involved countries to cooperate and the effectiveness of regulatory measures to enable transnational electricity exchange.

\subsection{Economic costs}

All five studies contain discussions of the economic costs associated with power system transformation. However, the results can only very roughly be compared, as each model uses its own cost metrics and its own assumptions for discount factors, technology costs and fuel price developments. Furthermore, the studies' results are often displayed in such a way, that the cost incurred by the North African countries cannot clearly be discerned: Only Brand (2013) exclusively focuses on the five North African countries; OME (2011) and Fragkos et al. (2012a) link their cost results to the group of MED-24 or the MED-9 countries, while Dii (2013) and Haller et al. (2012) aggregate the costs of the entire EU-MENA region. Due to these differences, this chapter can only draw some general conclusions about the studies' most significant cost patterns.

Most studies demonstrate that renewable energy integration in North Africa is an economically viable business case compared to strategies of conventional power system expansion. Avoided investments in conventional power plants and avoided costs for fossil fuels have the potential to offset the investments in capital-intensive RES-E expansion. For instance, OME's study reveals that between 2012 and 2030, the renewable-friendly "Proactive" scenario brings about natural gas savings worth $€ 100 \mathrm{bn}$ for the Southern Mediterranean region. These savings largely exceed the additional costs of renewable energy investments ( $€ 30 \mathrm{bn}$, compared to the "Conservative" scenario) - resulting in net savings on the order of $€ 70 \mathrm{bn}$. Fragkos et al.'s study also confirms the finding that renewable energy expansion can be a financially attractive alternative, especially if seen in light of the heavy fossil fuel subsidies that many MENA economies are shouldering to keep energy prices low. Until the time horizon of 2030, the scenarios "MED-EU Integration" and "Global Integration", both characterized by strong RES-E ambitions and an accelerated removal of energy subsidies, accumulate total system cost savings for the MED-9 countries of more than

12 A 3000 MW submarine interconnection project between Saudi Arabia and Egypt is currently under construction. 
$€ 150 \mathrm{bn}$ compared to the fossil fuel-dominated "Reference" scenario that features only a partial removal of energy subsidies.

It must be mentioned that the above-described positive cost outlooks for renewable integration are only valid in the scenarios where renewable energy penetration in the electricity mix is still relatively moderate. If wind and solar technologies fully take over power generation (nearing 100\% RES-E supply as in Dii, 2013 or Haller et al., 2012 ), increased costs for the overall system are the consequence due to higher requirements in transmission capacity, higher curtailment of intermittent power generation and a greater need for storage-bound RES technologies, such as cost-intensive CSP plants. Hence, the 'last percentage points' to reach a fully renewable-based power system are the most expensive also for the North African power systems. In Dii's study, the costs of reaching an almost $100 \%$ renewable energy supply (the "Connected" scenario by 2050) are higher by €23bn compared to the "Inertia" scenario with a relatively lower share of RES-E. Haller et al.'s decarbonization scenarios likewise demonstrate (by means of cumulative distribution functions of electricity prices) that very high RES-E penetration comes at additional costs for the EU-MENA region.

A second finding is that increased cooperation and integrated system planning generally reduces the costs of power system transformation. The effect of cooperation on interconnected power systems and market integration in North Africa is, for instance, analyzed by Brand (2013) who contrasted two cases of cooperation for the North African region: one with strong efforts to integrate power markets and the joint use of transnational interconnectors for electricity exchanges; the other with only low-profile cooperation. The results indicate that the effect of cooperative behavior and mutual use of transnational power transmission results in benefits of around $€ 3.4 \mathrm{bn}$ by 2030 . Haller et al. also examined the cost advantages of integrated power systems. Although the authors focus on the entire EU-MENA region and not exclusively the five North African countries, clear benefits of cooperation can be observed: In a cooperative environment ("PolGrid"), average electricity prices in 2050 are approximately $13 \%$ lower than in the "PolNoGrid" scenario where transcontinental transmission grid expansion is suppressed. Clear cost benefits of EU-MENA power system integration are also the result of Dii's study Getting Started (Dii, 2013), which calculated 5\% lower electricity prices for the "Connected" compared to the "Disconnected" scenario, which disables interconnectors between Europe and the MENA region. 


\section{Conclusion}

This paper has analyzed five different studies dealing with long-term renewable energy expansion scenarios for the North African electricity systems. All studies employ technoeconomic energy system modeling techniques. This ensures that the proposed transformation pathways stay technically feasible and economically optimized over the long time scales of the scenarios. The appeal of such quantitative models is that they produce tangible, 'calculated' results - making them attractive for stakeholders to prove the cogency of their studies while conveying recommendations to policy makers. Weaknesses, however, lie in the manifold possibilities of influencing the model outcomes, e.g. by modifying parameter settings or by applying exogenous, normative constraints to the modeling process. Often, the high degree of technical sophistication of models conceals that scenario outcomes can be influenced by a priori assumptions of the modelers. As our paper shows, many studies build on constraints set by the authors. The studies with a 2050 scenario horizon, for example, assume the success of climate action in the North African region and the opening of crosscontinental electricity markets to electricity transmission over large distances. Not surprisingly, such assumptions lead to model results suggesting large-scale RES-E expansion in the region - even exceeding the domestic power demand of North Africa itself. The three 2030 scenario studies exhibit more moderate perspectives for RES-E integration, because their forecasting approaches still consider an important contribution of conventional, fossil fuel-based, power generation. In these studies, diverging outlooks are observed for the future of coal and nuclear power in North Africa. In all studies, i.e. the 2030 as well as the 2050 scenarios, there also is no coherent picture of RES-E technology preferences in the North African electricity mix. The results diverge on the expected proportions of solar and wind technologies: While some studies favor wind power, the others give preference to solar PV and, particularly, CSP technologies. A high degree of heterogeneity across all studies is also observed with regards to the options of North African countries to export electricity.

Despite these discrepancies, it can be stated that the five publications constitute a highly valuable contribution to the current research on North African electricity strategies. The studies demonstrate in a coherent and robust manner that RES-E integration into the regional power systems is technically and economically feasible - even up to very high degrees of penetration. By examining the conditions and limitations of these schemes within integrated power systems, the studies also shed more light on the viability of electricity exports to 
Europe. For instance, it is certainly helpful for North African energy planners to know that integrated EU-MENA electricity markets can only enable large-scale electricity exports to Europe, if very high levels of RES-E penetration are reached in North Africa. Consequently, a delayed RES-E expansion would result in a postponement of potential power exports. Thanks to the inter-temporal modeling approaches, these interdependencies are better understood.

Of course, techno-economic models can only describe system transformation pathways within specific scenario frameworks. For this meta-analysis, it was an opportune coincidence that the presented studies cover a broad variety of scenarios: ranging from optimistic, vision-driven scenarios to rather dismal frameworks characterized by political instability and regulatory constraints. It is true that at the moment, the situation mostly corresponds to the latter case, as many North African countries are still shaken by instability and economic downturn following the events of the Arab Spring. In this context it might be helpful to keep in mind that, setting aside the promise of large transcontinental export schemes, it would be economically beneficial for the North African power systems to pursue smaller, incremental efforts to integrate RES-E, and possibly focus on more locally based power system cooperation.

\section{Acknowledgements}

The authors would like to thank Lisa Guarrera (OME), Pantelis Capros and Panagiotis Fragkos (University of Athens), Frank Sensfuß (Fraunhofer ISI), Florian Zickfeld and Philipp Godron (Dii) as well as Markus Haller and Paul Nahmmacher (PIK) for helpful comments and for sharing details of their model results.

\section{References}

Ben Romdhane, S., Razavi, H., Santi, E., 2013. Prospects for an integrated North Africa energy market: Opportunities and lessons. Energy Strategy Reviews 2 (2013) 100-107. doi: 10.1016/j.esr.2013.04.005

Boie, I., Pudlik, M., Ragwitz, M., Sensfuß, F., Bohn, F., Agsten, M., Bretschneider, P., Westermann, D., 2014. Scenarios for renewable energy deployment in North African countries and electricity exchange with Europe - A model-based analysis for 2050. International Journal of Smart Grid and Clean Energy, Vol. 3, No. 3 , July 2014. 
Brancucci Martínez-Anido, C., et al., 2013 Effects of North-African electricity import on the European and the Italian power systems: a techno-economic analysis. Electric Power Systems Research (96): 119-132. doi: 10.1016/j.epsr.2012.11.001

Brand, B., 2013, Transmission topologies for the integration of renewable power into the electricity systems of North Africa. Energy Policy. http://dx.doi.org/10.1016/ j.enpol.2013.04.071

Brand, B., Zingerle, J., 2010. The renewable energy targets of the Maghreb countries: impact on electricity supply and conventional power markets. Energy Policy 39(8), 44114419., http://dx.doi.org/10.1016/j.enpol.2010.10.010.

Capros, P., Paroussos, L., Fragkos, P., Tsani, S., Boitier, B., Wagner, F., Bollen, J., 2014. Description of models and scenarios used to assess European decarbonisation pathways. Energy Strategy Reviews http://dx.doi.org/10.1016/ j.esr.2013.12.008

Chedid, R., Chaaban, F., Salameh, S., 2001. Policy analysis of greenhouse gas emissions: the case of the Lebanese electricity sector. Energy Conversion and Management 42, 373392.

Czisch, G., 2005. Szenarien zur zukünftigen Stromversorgung. Kostenoptimierte Variationen zur Versorgung Europas und seiner Nachbarn mit Strom aus erneuerbaren Energien, $\mathrm{PhD}$ Thesis, Kassel

Dii, 2012. Desert Power 2050. Perspectives on a Sustainable Power System for EUMENA. Munich, June 2012. < http://www.dii-eumena.com/dp2050.html>

Dii, 2013. Desert Power : Getting Started. Munich, June 2013. < http://www.diieumena.com/dp2050/getting-started.html>.

Dii, 2014. Vision and Mission. < http://www.dii-eumena.com/about-us/mission-vision.html >. Munich.

DLR, 2005. Concentrating Solar Power for the Mediterranean Region. Final Report by German Aerospace Center (DLR), commissioned by Federal Ministry for the Environment, Nature Conservation and Nuclear Safety, Stuttgart.

DLR, 2006. TRANS-CSP: Trans-Mediterranean Interconnection for Concentrating Solar Power. German Aerospace Center, Stuttgart.

DLR, 2009. Characterization of Solar Electricity Import Corridors from MENA to Europe. German Aerospace Center, Stuttgart.

El Fadel, M., Rachid, G., El-Samra, R., Bou Boutros, G., Hashisho, J., 2012. Emissions reduction and economic implications of renewable energy market penetration of power generation for residential consumption in the MENA region. Energy Policy 52, 618-627. doi:10.1016/j.enpol.2012.10.015 
EU Directive, 2009. EU Directive 2009/28/EC of the European Parliament and of the Council of 23 April 2009 on the promotion of the use of energy from renewable sources, in: Official Journal of the European Union, 5.6.2009, L140/16-62.

EWI/Energynautics, 2011. Roadmap 2050-A Closer Look: Cost-efficient RES-E Penetration and the Role of Grid Extensions. Cologne, October 2011.

Fragkos, P., Kouvaritakis, N., Capros, P., 2012. Model-based analysis of the future strategies for the MENA energy system. Energy Strategy Reviews. http://dx.doi.org/ 10.1016/j.esr.2012.12.009

Fragkos, P., Kouvaritakis, N., Capros, P., 2012. Prospects for Energy Supply and Demand in the Southern Mediterranean: Scenarios for 2010-30. MEDPRO Technical Report No. 22. December 2012. <www.medpro-foresight.eu>

Haddad, M., 2011. Country perspective Tunisia. In: The end of nuclear energy. International perspectives after Fukushima. (Eds. Netzer N and Steinhilber J). Friedrich Ebert Stiftung, July 2011. Berlin.

Haller, M., Ludig, K., Bauer, N., 2012. Decarbonization scenarios for the EU and MENA power system: Considering spatial distribution and short term dynamics of renewable generation. Energy Policy. http://dx.doi.org/10.1016/j.enpol.2012.04.069

Huber, M., Dorfner, J., Hamacher, T., 2012. Electricity system optimization in the EUMENA region. Technical Report. Munich.

IEA 2011. World Energy Outlook 2011, International Energy Agency. Paris, France.

IEA, 2012. $\mathrm{CO}_{2}$ Emissions from Fuel Combustion. 2012 Edition. International Energy Agency. Paris, France.

IEA, 2013. Energy Balances of Non-OECD Countries. 2012 Edition. International Energy Agency. Paris, France.

Jewell, J., 2011. A nuclear-powered North Africa: Just a desert mirage or is there something on the horizon? Energy Policy, 39(8), 4445-4457. doi:10.1016/j.enpol.2010.09.042

Knies, G., Czisch, G. Brauch, H., 1999. Regenerativer Strom für Europa durch Fernübertragung elektrischer Energie, Energiestudien 1, AFES-PRESS Report No. 67. Mosbach.

May, N., 2005. Eco-balance of a solar electricity transmission from North Africa to Europe. Unpublished Diploma thesis, Technical University of Braunschweig. 2005.

MED-EMIP, 2010. Medring Update Study, Vol I-IV. Euro-Mediterranean Energy Market Integration Project, Final Draft, April 2010. <http://ec.europa.eu/energy/ international/studies/external_dimension_en.htm/>

MedGrid, 2014. MedGrid - Our Vision <http://www.medgrid-psm.com/en/project/thevision/>. Paris. 
Mercados, 2011. Guide des outils de planification du système électrique pour améliorer l'intégration de l'énergie renouvelable. Application à la région du Maghreb. Madrid, November 2011

NEPCO, 2012. National Electric Power Company (NEPCO). Annual Report 2012. Amman, Jordan.

OME, 2011. Mediterranean Energy Perspectives 2011. Observatoire Méditerranéen de 1'Energie. Nanterre, 2011. <www.ome.org >

ONEE, 2012. Office National de l'Electricité et de l'Eau potable (ONEE). Depliant statistique 2012. Casablanca.

REN 21, 2013. MENA Renewable Status Report 2013. REN21 Secretariat, Paris, France. May 2013

Sensfuß, F., Ragwitz, M., Genoese, M. (2008). The merit-order effect: A detailed analysis of the price effect of renewable electricity generation on spot market prices in Germany. Energy policy, 36(8), 3086-3094. doi: 10.1016/j.enpol.2008.03.035

Staiss, F; Böhnisch, H., Mößlein, J., Pfisterer, F., Stellbogen, D., 1994. Photovoltaische Stromerzeugung, Import solarer Elektrizität, Wasserstoff. Zentrum für Sonnenenergieund Wasserstoff-Forschung. Stuttgart.

Supersberger, N., Abedou, A., Brand, B., Ferfera, M. Y., Kumetat, D., Hammouda, N. E., Kennouche, T, Boucherf, K., Ziour, H., 2010. Algeria- A Future Supplier of Electricity from Renewable Energies for Europe? Wuppertal Institute for Climate, Environment and Energy, Wuppertal, Germany and CREAD, Algiers.

Thiam, B., 2013. Energies renouvelables: Le grand match solaire/éolien. Economiste (4119) 24.09.2013. Casablanca. < www.leconomiste.com $>$.

Trieb, F., Schillings, C., Pregger, T., O'Sullivan, M., 2012. Solar electricity imports from the Middle East and North Africa to Europe. Energy Policy, 42, 341-353. doi: 10.1016/j.enpol.2011.11.091

UfM, 2014. Union for the Mediterranean - The Mediterranean Solar Plan. $<$ http://ufmsecretariat.org/mediterranean-solar-plan/ > . Barcelona.

World Bank, 2011. Project appraisal document on a proposed loan in the amount of US\$200 million and a proposed Clean Technology Fund loan in the amount of US\$97 million to the Moroccan Energy for Solar Energy (MASEN) with a guarantee of the Kingdom of Morocco for the Ouarzazate I Concentrated Solar Power Plant Project. Report No: 64663-MA. The World Bank, Washington, 2011.

Wuppertal Institut/Alcor, 2011. Etude Stratégique du Mix Energétique pour la Production d'Electricité en Tunisie, Tunis 2011. <epub.wupperinst.org/files/4785/ 4785_Mix_Energetique_Tunisie.pdf $>$ 